\title{
Epidemiology and genotypic diversity of human metapneumovirus in paediatric patients with acute respiratory infection in Beijing, China
}

Chao Wang ${ }^{1 \dagger}$, Tianli Wei ${ }^{2 \dagger}$, Fenlian Ma ${ }^{1}$, Hao Wang ${ }^{1}$, Jianqiang Guo ${ }^{1}$, Aijun Chen ${ }^{1}$, Yiman Huang ${ }^{1}$, Zhiping Xie ${ }^{1 *}$ and Lishu Zheng ${ }^{1,3^{*}}$ (i)

\begin{abstract}
Background: Acute respiratory tract infections (ARTIs) causes high amounts of morbidity and mortality worldwide every year. Human metapneumovirus (HMPV) is a major pathogen of ARTIs in children. In this study, we aimed to investigate the epidemiology and genotypic diversity of HMPV in children hospitalized with ARTIs in Beijing, China.

Methods: Hospitalized children aged < 14 years with ARTIs were enrolled from April 2017 to March 2018; nasopharyngeal aspirates were collected and subjected to real-time polymerase chain reaction tests for HMPV. HMPVpositive samples were genotyped based on a partial $\mathrm{N}$ gene. Whole genome sequences were determined for samples with high viral loads.

Results: $4.08 \%$ (52/1276) enrolled paediatric patients were identified as having HMPV infection. The epidemic season is winter and early spring, children aged $\leq 4$ years were more susceptible to HMPV infection $(47 / 52,90.38 \%)$. The coinfection rate were $36.54 \%$ (19/52), the most common co-infected virus were influenza and respiratory syncytial virus. The main diagnoses of HMPV infection were pneumonia $(29 / 52,55.77 \%)$ and bronchitis $(23 / 52,44.23 \%)$, while the main clinical manifestations were cough, fever, rhinorrhoea, and sneeze. Among $48 \mathrm{HMPV}$-positive specimens, A2b $(19 / 48,39.58 \%)$ and B1 $(26 / 48,54.17 \%)$ were the main epidemic subtypes. Patients with HMPV genotype A infection had a higher viral load compared to genotype B patients (6.07 vs. $5.37 \log _{10}$ RNA copies/ml). Five complete sequences of HMPV were obtained. This is the first report of a whole genome sequence of HMPV-B1 isolated in China.

Conclusions: HMPV is an important respiratory pathogen in paediatric patients. Cases of HMPV infection could burden hospitals in the epidemic season. HMPV viral loads and genotypes have no correlation with co-infection or clinical characteristics.
\end{abstract}

Keywords: Human metapneumovirus, Epidemiology, Genetic diversity, Pediatric, Respiratory tract infection

*Correspondence: xiezhiping@126.com; zhengls@ivdc.chinacdc.cn ${ }^{\dagger}$ Chao Wang and Tianli Wei have contributed equally to this work ${ }^{1} \mathrm{NHC}$ Key Laboratory of Medical Virology and Viral Diseases, National Institute for Viral Disease Control and Prevention, China CDC, Beijing, China

Full list of author information is available at the end of the article

\section{Background}

Human metapneumovirus (HMPV) is an enveloped, nonsegmented virus, with a negative-sense, single-stranded RNA genome, classified in the Metapneumovirus genus within the family Pneumovirinae. Since HMPV was first detected in 2001 [1], it has been determined to be one of the most common pathogens of acute respiratory tract original author(s) and the source, provide a link to the Creative Commons licence, and indicate if changes were made. The images or other third party material in this article are included in the article's Creative Commons licence, unless indicated otherwise in a credit line to the material. If material is not included in the article's Creative Commons licence and your intended use is not permitted by statutory regulation or exceeds the permitted use, you will need to obtain permission directly from the copyright holder. To view a copy of this licence, visit http://creativecommons.org/licenses/by/4.0/. The Creative Commons Public Domain Dedication waiver (http://creativeco mmons.org/publicdomain/zero/1.0/) applies to the data made available in this article, unless otherwise stated in a credit line to the data. 
infections (ARTIs) among all age groups, particularly affecting children, the elderly, and immunocompromised individuals [2, 3]. HMPV can cause both upper and lower respiratory tract infection (URTI and LRTI). The clinical symptoms of HMPV infection are similar to those of respiratory syncytial virus (RSV) infection, i.e. non-productive cough, fever, rhinorrhoea, and wheezing [2, 4].

The HMPV genome is about $13 \mathrm{~Kb}$ in length and is composed of eight genes encoding nine proteins: $3^{\prime}-\mathrm{N}, \mathrm{P}$, M, F, M2-1/M2-2, SH, G, L-5'. Based on gene sequences for the nucleoprotein $(\mathrm{N})$, fusion protein $(\mathrm{F})$, and glycoprotein (G), HMPV can be divided into five subtypes (A1, A2a, A2b, B1, and B2) [5, 6]. Some studies have identified other subtypes [7-9], such as A2c, B2a, and B2b, but the prevalence of these new subtypes requires support from more epidemiological data. At present, the correlation between HMPV genotypes and the severity of illness remains unclear.

In this study, we describe the prevalence rate, co-infection status, and clinical characteristics of HMPV in paediatric patients with ARTIs. Additionally, we explore the association between viral loads and symptoms of HMPVinfected patients and analyse the distribution of HMPV genotypes in Beijing, China. We also obtained five whole genome sequences of HMPV.

\section{Materials and methods}

\section{Study population and specimen collection}

From April 2017 to March 2018, nasopharyngeal aspirates (NPAs) were collected from children (aged $<14$ years) with ARTIs who were hospitalized in the Beijing Friendship hospital. ARTIs were defined by the presence of at least two of the following symptoms: fever, cough, sneeze, wheezing, nasal obstruction, sore throat, and dyspnoea. Children who had been enrolled but discharged were considered as a new case if they were readmitted for a new episode of ARTIs. Demographic data and clinical characteristics were recorded on a form from each patient's record of medical history and examination. All NPAs were collected in tubes with viral transport medium and kept at $-80^{\circ} \mathrm{C}$ until use.

\section{Detection of HMPV}

The viral nucleic acids were extracted from $200 \mu \mathrm{l}$ of each specimen with a QIAamp MinElute Kit (Qiagen, Germany) in accordance with the manufacture's protocols. HMPV was identified by using a One-step RT-PCR Kit (Ambion, USA) in accordance with the manufacture's protocols. HMPV forward primer (5'-CATATAAGCATG CTATATTAAAAGAGTCTC- $\left.3^{\prime}\right)$, reverse primer $\left(5^{\prime}\right.$ CCTATTTCTGCAGCATATTTGTAATCAG-3'), and probe (FAM-TGYAATGATGAGGGTGTCACTGCG GTTG-TAMRA) were used as previously described [10] to amplify a 163-bp fragment from the $\mathrm{N}$ gene. PCRpositive products were confirmed by sequencing. Viral loads were detected by real-time reverse transcription PCR (qRT-PCR), and the standard curve was generated as described previously [11].

\section{Detection of common respiratory viruses}

HMPV-positive specimens were screened for 16 common respiratory viruses: influenza virus types A-C (IFV), parainfluenza virus types 1-4 (HPIV), human coronaviruses HKU1/229E/OC43/NL63 ( $\mathrm{HCoV})$, respiratory syncytial virus (RSV), human rhinovirus (HRV), human bocavirus ( $\mathrm{HBoV}$ ), adenovirus (ADV), and WU polyomavirus (WUPyV). All viruses were assayed by real-time PCR, and RNA viruses were tested using an AgPath$\mathrm{ID}^{\mathrm{TM}}$ One-Step RT-PCR Kit (Ambion), DNA viruses were tested using TaqMan ${ }^{\mathrm{TM}}$ Gene Expression Master Mix (Thermo Fisher, USA).

\section{HMPV genotyping}

HMPV cDNA was synthesized using SuperScript III First-Strand Synthesis System for Reverse TranscriptionPCR (RT-PCR) (Invitrogen, USA) in accordance with the manufacture's protocols. The partial sequence of $\mathrm{N}$ gene (1200 bp) was amplified using a nested PCR under the following thermocycling conditions: an initial denaturing at $94{ }^{\circ} \mathrm{C}$ for $5 \mathrm{~min}$, followed by 35 cycles of $94{ }^{\circ} \mathrm{C}$ for $40 \mathrm{~s}, 46^{\circ} \mathrm{C}$ for $40 \mathrm{~s}$, and $72{ }^{\circ} \mathrm{C}$ for $1 \mathrm{~min}$, and a final extension at $72{ }^{\circ} \mathrm{C}$ for $10 \mathrm{~min}$. The following newly designed primers were used: outer forward primer, $5^{\prime}$-TTAART TACAAAAAAACATGGGAC-3'; outer reverse primer, 5'-AAAGAATATCTTTTCCTTCAGGG-3'; internal forward primer, $5^{\prime}$-ATGGGACAAGTGAAAATGTCTC- ${ }^{\prime}$; and internal reverse primer, 5'-AATTACTCATAATCA TTTTGACTG-3'. Specimens that failed to be amplified were considered as untyped. The PCR products were sequenced by Sanger sequencing (TSINGKE, Beijing, China). A neighbour-joining (NJ) tree was constructed by the Tamura-Nei model in MEGA 7.0 using 1000 bootstrap replicates. The web server of FindModel (https://www.hiv.lanl.gov/content/sequence/findmodel/ findmodel.html) was used to find best available nucleotide substitution model. Reference strains of HMPV were acquired from GenBank, including AF371337, AY297749, DQ843659, AY525843, and FJ168778. Avian metapneumovirus C (AMPV C, AY590688) was used as an outgroup to root the tree.

\section{Sequencing}

HMPV-positive samples with high copy numbers $\left(>10^{5}\right.$ copies $/ \mathrm{ml}$ ) were further used for whole genome sequencing. Fourteen pairs of primers with overlap were designed according to the reference strain CAN97-83 (GenBank 
accession number: AY297749) (Table 1). Ex-Taq (TaKaRa, China) was used to perform PCR. The PCR products were sequenced by Sanger sequencing, and the resulting sequences were assembled using Sequencher 5.0. Comparisons were made using published HMPV sequences selected from GenBank. A NJ-tree was constructed using the Tajima-Nei model (MEGA 7.0) with 1000 bootstrap replicates. Identity within the analysed sequences was analysed by BioEdit. Recombination events were detected by Simplot.

\section{Statistical analysis}

Data analysis was performed using SPSS 13.0, and categorical data was compared by $x^{2}$ and Fisher's exact tests. Two-tailed $p$ values of $<0.05$ were considered to indicate statistical significance.

\section{Results}

Epidemiology of HMPV

A total of 1276 hospitalized children with ARTIs were enrolled between April 2017 and March 2018; 4.1\% (52/1276) of their samples were positive for HMPV. As shown in Table 2, the male/female ratio was 1.26 (29:23) $(p=0.251)$, indicating the sex difference was not statistically significant. The median age of HMPV-infected children was 36 months (IQR: 1-168 months), and the detection rates were significantly different among different age groups $(p=0.019)$. The HMPV prevalence of patients aged $\leq 4$ years $(47 / 898,5.2 \%)$ was significantly higher than that of patients aged $4-14$ years $(5 / 378,1.3 \%)$ $(p=0.001)$. The seasonal distribution of HMPV infection from April 2017 to March 2018 is shown in Fig. 1. 59.6\% $(31 / 52)$ of positives were found in spring, none $(0 / 52)$ in summer, $3.8 \%(2 / 52)$ in autumn and $36.5 \%(19 / 52)$ in

Table 1 Primer sets for amplification of the whole genome of HMPV

\begin{tabular}{|c|c|c|c|c|}
\hline Target genes & Primers & Primer sequence $\left(5^{\prime}-3^{\prime}\right)$ & Location $(n t)^{a}$ & $\begin{array}{l}\text { Annealing } \\
\text { temp }\left({ }^{\circ} \mathrm{C}\right)\end{array}$ \\
\hline \multirow[t]{2}{*}{ N } & $N(F)$ & GCGAAAAAAACGCGTATA & $3-20$ & 50 \\
\hline & $N(R)$ & TTGCTGCTTCATTACCCAT & $1296-1314$ & \\
\hline \multirow[t]{2}{*}{$P$} & $P(F)$ & GAAGAAAAAGARGCTGCAGA & $1178-1196$ & 50 \\
\hline & $P(R)$ & CCAGATCAACTTGAACAGC & $2228-2246$ & \\
\hline \multirow[t]{2}{*}{ M } & $M(F)$ & GAATCMGAAGAAGAAGAAG & $2070-2088$ & 50 \\
\hline & $M(R)$ & CAYCACTTTCCAAGACATT & $3066-3084$ & \\
\hline \multirow[t]{4}{*}{$\mathrm{F}$} & $F-1(F)$ & CAATCMAAAAGGYATATTC & $2800-2818$ & 50.2 \\
\hline & $F-1(R)$ & CTGCAGATGTYGGCATGT & $3764-3781$ & \\
\hline & $F-2(F)$ & CAGTCAATTCAACAGAAG & $3645-3662$ & 50 \\
\hline & $F-2(R)$ & TTCATATTTGCATGGAGC & $4736-4753$ & \\
\hline \multirow[t]{2}{*}{ M2 } & $\mathrm{M} 2(\mathrm{~F})$ & CCTCCAGAGCTGARTGGTGT & $4636-4655$ & 50 \\
\hline & $M 2(R)$ & TWTCATTGTCAYTTATCCCA & $5467-5486$ & \\
\hline \multirow[t]{2}{*}{$\mathrm{SH}$} & $\mathrm{SH}(\mathrm{F})$ & GCAAGACAGTGAAAGCAYT & $5254-5272$ & 46.8 \\
\hline & $\mathrm{SH}(\mathrm{R})$ & CATCYTTGCTTTGARCAT & $6268-6285$ & \\
\hline \multirow[t]{2}{*}{ G } & $G(F)$ & AAACAARAAWATGGGACAAG & $6207-6226$ & 50 \\
\hline & $G(R)$ & TAGACATTRACAGTRGAYTC & $7148-7167$ & \\
\hline \multirow[t]{12}{*}{ L } & $L-1(F)$ & GACAAATRRCAATGGATC & $7122-7139$ & 44.7 \\
\hline & $L-1(R)$ & TAGTTCTGTYAARCTCTC & $8303-8320$ & \\
\hline & $L-2(F)$ & GARAATGCTGCWGAATTA & $8186-8203$ & 46.8 \\
\hline & $L-2(R)$ & GATATHGCYTCCATTGTCC & 9288-9306 & \\
\hline & $L-3(F)$ & ACATGCACCACCAGAAAC & 9178-9195 & 46.8 \\
\hline & $L-3(R)$ & AGGTGTTATGTTKTCWGC & $10,238-10,225$ & \\
\hline & $L-4(F)$ & GTGAYATMAATAGAACAGC & $10,128-10,146$ & 43.8 \\
\hline & $L-4(R)$ & ACTGAAGATRTGTTGATC & $11,231-11,248$ & \\
\hline & $L-5(F)$ & GGAATTAGYATAATGAGTG & $11,081-11,099$ & 48 \\
\hline & $L-5(R)$ & GGATATTCACATGCTGTTC & $12,246-12,264$ & \\
\hline & $L-6(F)$ & CTAACAAGRAATTACATG & $12,071-12,088$ & 48 \\
\hline & $L-6(R)$ & ACGGCAAAAAAACCGTAT & $13,318-13,335$ & \\
\hline
\end{tabular}

\footnotetext{
a The reference of location is based on AY297749 strain
} 
Table 2 Population demographic of HMPV-positive specimens from April 2017 and March 2018

\begin{tabular}{lcclc}
\hline Variable & $\begin{array}{l}\text { Number } \\
\text { of patient }\end{array}$ & $\begin{array}{l}\text { Number of HMPV } \\
\text { positive children }\end{array}$ & $\begin{array}{l}\text { Prevalence } \\
\text { of HMPV (\%) }\end{array}$ & $\boldsymbol{p}$ value \\
\hline Gender & & & & 0.251 \\
Male & 674 & 29 & 4.30 & \\
Female & 602 & 23 & 3.82 & 0.019 \\
Age (years) & & & & \\
$\leq 1$ & 340 & 13 & 3.82 & \\
$>1$ to $\leq 2$ & 137 & 9 & 6.57 & \\
$>$ 2 to $\leq 3$ & 281 & 17 & 6.05 & \\
$>3$ to $\leq 4$ & 140 & 8 & 5.71 & \\
$>4$ to $\leq 5$ & 86 & 0 & 0 & \\
$>5$ to $\leq 7$ & 121 & 4 & 3.30 & \\
$>7$ to $\leq 14$ & 171 & 1 & 0.58 & \\
Total & 1276 & 52 & 4.08 & \\
\end{tabular}

winter. The detection frequencies peaked in March 2018 (20/129, 15.5\%).

\section{Co-infection with other respiratory viruses}

Among the 52 HMPV-infected children, 36.5\% (19/52) were co-infected with other respiratory viruses (Table 3 ). Most co-infections involved RSV or IFV-A, (both account for $11.5 \%, 6 / 19)$. The linear range of the standard curve of the $\mathrm{N}$-gene is $10^{3}-10^{12}$ copies $/ \mathrm{ml}$. The viral loads of HMPV-positive patients ranged from $7 \times 10^{3}$ to $9.61 \times 10^{7}$ copies $/ \mathrm{ml}$. At the single time point when the viral load was measured, there was no statistical difference in the viral loads between HMPV mono-infections and co-infections ( $p=0.398)$ (Fig. 2$)$, and the viral loads had no relationship with the tested demographic or clinical features (i.e. gender, age, temperature, and hospitalization; data not shown).

\section{Clinical characteristics of HMPV infections}

The clinical characteristics, diagnoses, and hospital stay lengths of HMPV-positive patients are listed in Table 4. The main clinical symptoms of HMPV infections included cough $(98.1 \%, 51 / 52)$ and fever (temperature of $\left.\geq 38{ }^{\circ} \mathrm{C} ; 90.4 \%, 47 / 52\right)$; other common symptoms included rhinorrhoea $(46.2 \%, 24 / 52)$, sneeze $(26.9 \%$, $14 / 52)$, shiver $(21.2 \%, 11 / 52)$, and nasal obstruction $(19.2 \%, 10 / 52)$. The duration of hospital stay for HMPVinfected children ranged from 4 to 18 days (mean: $6.75 \pm 2.87$ days), with most patients $(78.9 \%, 41 / 52)$ being discharged within 7 days. Of the 52 HMPV-infected children, all were diagnosed with a LRTI, 94.2\% (49/52) had an abnormal chest radiograph, 55.8\% (29/52) had pneumonia, and $44.2 \%(23 / 52)$ had bronchitis. There was no significant difference in these symptoms between the HMPV-positive patients with co-infections and those without co-infections. Additionally, hospital stay, fever and cough have no significant difference between patients aged $<2$ years and $2-14$ years $(P=0.05,0.187$, 1.00 , respectively).

\section{Phylogenetic analysis of HMPV}

A portion of the $\mathrm{N}$ gene (813 bp) was amplified in 48 HMPV-positive specimens (the sequences are available in Additional file 1). The phylogenetic analysis conducted on these sequences revealed that $39.6 \%(19 / 48)$

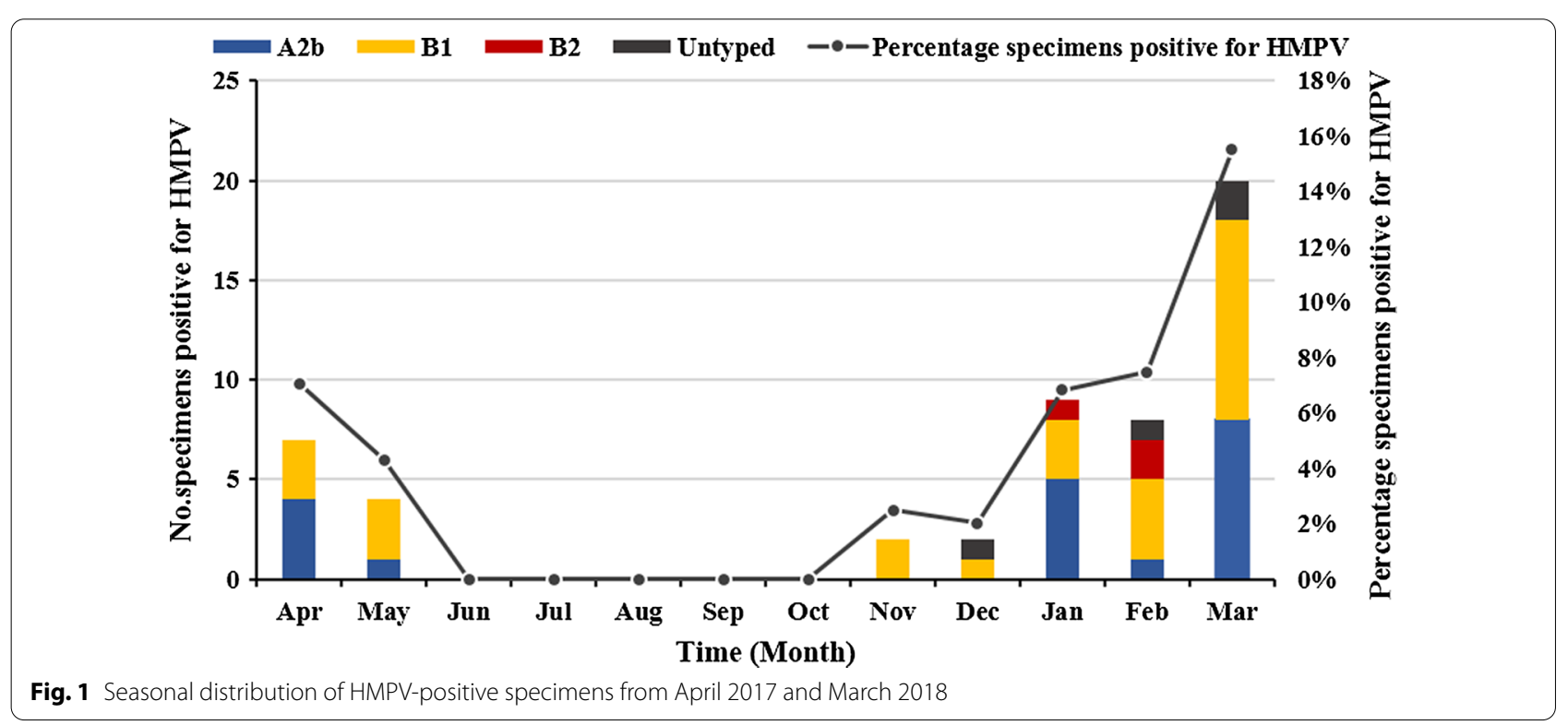


Table 3 Co-detections of HMPV and other respiratory virus in the study

\begin{tabular}{|c|c|c|}
\hline Groups & Co-infection viruses & NO. (\%) \\
\hline \multirow[t]{7}{*}{2 viruses $(n=14)$} & $\mathrm{HMPV}+\mathrm{IFV}$ & $4(21.1)$ \\
\hline & $\mathrm{HMPV}+\mathrm{RSV}$ & $3(15.8)$ \\
\hline & $\mathrm{HMPV}+\mathrm{HRV}$ & $2(10.5)$ \\
\hline & HMPV + WUPyV & $2(10.5)$ \\
\hline & HMPV + ADV & $1(5.3)$ \\
\hline & $\mathrm{HMPV}+\mathrm{HCOV}$ & $1(5.3)$ \\
\hline & $\mathrm{HMPV}+\mathrm{HBOV}$ & $1(5.3)$ \\
\hline \multirow[t]{2}{*}{3 viruses $(n=3)$} & HMPV + IFV + RSV & $2(10.5)$ \\
\hline & HMPV + HRV + WUPYV & $1(5.3)$ \\
\hline 4 viruses $(n=1)$ & $\mathrm{HMPV}+\mathrm{HPIV}+\mathrm{HCOV}+\mathrm{ADV}$ & $1(5.3)$ \\
\hline 5 viruses $(n=1)$ & HMPV + HPIV + RSV + ADV + WUPyV & $1(5.3)$ \\
\hline
\end{tabular}

ADV adenovirus, HBoV human bocavirus, $\mathrm{HCoV}$ human coronavirus (HKU1/229E/ OC43/NL63), HPIV human parainfluenza virus 1-4, HRV human rhinovirus, IFV influenza virus A-C, RSV respiratory syncytial virus, WUPyVWU polyomavirus

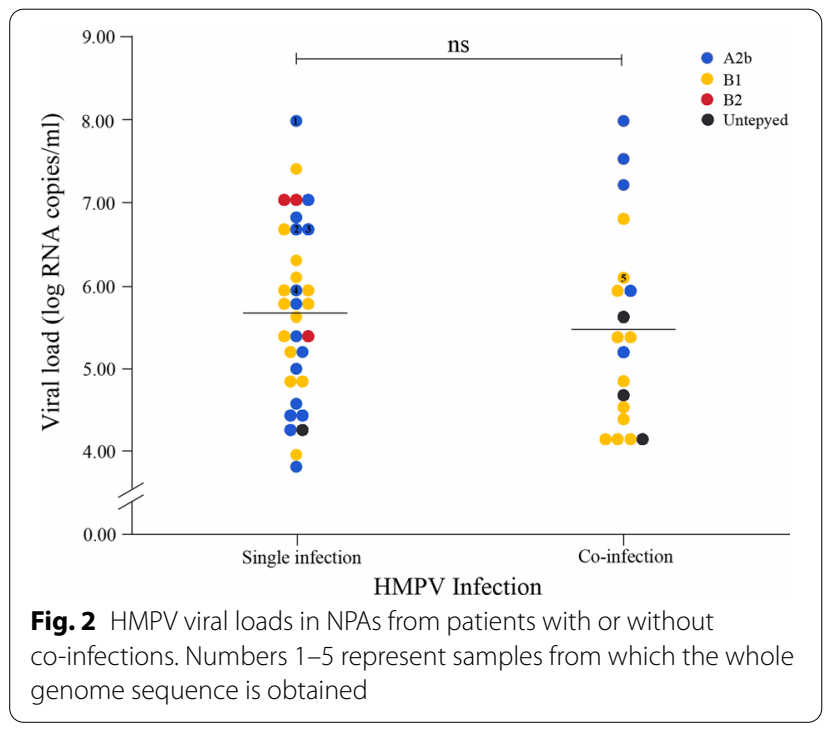

of strains were grouped into the A2b lineage, 54.2\% (26/48) of strains were grouped into the B1 lineage, and $6.3 \%(3 / 48)$ of strains were grouped into the B2 lineage; subtypes A1 and A2a were not detected (Fig. 3a). The positives rates of genotype $\mathrm{A} 2 \mathrm{~b}$ and $\mathrm{B} 1$ were higher in the spring $(23.1 \%, 12 / 52$ and $30.8 \%, 16 / 52$, respectively). Additionally, HMPV genotype A patients had a significantly higher viral load $\left(6.07 \pm 1.21 \log _{10}\right.$ RNA copies $/ \mathrm{ml}, \mathrm{n}=22)$ than genotype $B$ patients $(5.37 \pm 0.92$ $\log _{10}$ RNA copies/ml, $\left.\mathrm{n}=26\right)(p=0.029)$. There was no statistical difference in the main clinical features (i.e. gender, age, temperature, hospitalization, and virus loads) between patients infected with HMPV genotype
A and those infected with HMPV genotype B (data not shown).

\section{Whole genome analysis of HMPV}

To characterize the whole genome sequences of HMPV epidemic strains, genomes were obtained for five of the HMPV strains by using Sanger sequencing; the GenBank accession numbers for these sequences are MK820375 and MN745084 to MN745087. Thirty HMPV sequences were downloaded from GenBank as reference strains. The Simplot analyses showed no evidence of a recombination event (data not shown). A phylogenetic tree based on the whole-genome sequences of HMPV was constructed using the NJ method. The resulting phylogenetic tree shows that four strains from this study belong to the A2b lineage, and are closest to the gz-01 (China) strain in genetic distance. Additionally, the first complete genome (bj0123) of an HMPV-B1 genotype in China was obtained. The results was consistent with the phylogenetic tree constructed based on the partial $\mathrm{N}$ gene sequences (Fig. 3b). Fusion protein $(\mathrm{F})$ is an envelope protein of HMPV that has two functional sites. One is a cleavage site, Arg-Gln-Ser-Arg $\downarrow$ (RQSR $\downarrow$ ), which is important for fusion progress between HMPV and the host cell, and the other one is an Arg-Gly-Asp motif (RGD), which mediates the binding of virus and cellular $\alpha_{\mathrm{v}} \beta_{1}$ integrins $[12,13]$. Based on an alignment of the obtained HMPV sequences with reference sequences, there were no nucleotide mutations detected in these functional sites (data not shown). The sequence identity were $80.0-100.0 \%$ among all the analysed sequences, G gene and $\mathrm{SH}$ gene have high genetic variability (48.3$100.0 \%$ and $66.4-100.0 \%$, respectively). The identity among five obtained HMPV whole genomes were $80.1 \%$ 99.6\%, while the identity of the four A2b genomes were 99.1-99.6\%, and the identity between bj0123 and the four A2b genome is about $80.1 \%$.

\section{Discussion}

HMPV has been identified a leading cause of ARTIs since it was discovered in 2001. According to a serological study, HMPV infection has existed for at least 70 years [1]. Almost all children eventually become infected by HMPV, and adults can be re-infected by HMPV throughout their lives due to incomplete immunity. The prevalence of HMPV in children is approximately $2.0-18.2 \%$ $[4,14-16]$. In this study, we explored the epidemiology and genotypic diversity of HMPV within hospitalized children in Beijing, China from April 2017 to March 2018. Of the 1276 children, 52 (4.1\%) were positive for HMPV, while $2 \%$ in southern China (Guangzhou, 2014-2016) and 7.14\% in northern China (Beijing, 2010) $[4,17]$, indicating that the prevalence of HMPV could 
Table 4 Clinical features among HMPV-positive hospitalized children

\begin{tabular}{|c|c|c|c|c|}
\hline Clinical diagnoses and characteristics & $\begin{array}{l}\text { Single infection } \\
\text { NO. }(\%)(n=33)\end{array}$ & $\begin{array}{l}\text { Co-infection } \\
\text { NO. }(\%)(n=19)\end{array}$ & $\begin{array}{l}\text { Total } \\
\text { NO. }(\%)(n=52)\end{array}$ & $p$ \\
\hline Bronchitis & $14(42.4)$ & $9(47.4)$ & $23(44.2)$ & $0.730^{\mathrm{a}}$ \\
\hline Pneumonia & $19(57.6)$ & $10(52.6)$ & $29(55.8)$ & \\
\hline Abnormal chest radiograph & $31(94.0)$ & $18(94.7)$ & $49(94.2)$ & $1.000^{\mathrm{b}}$ \\
\hline Hospitalization > 7d & $5(15.2)$ & $6(31.6)$ & $11(21.2)$ & $0.296^{b}$ \\
\hline Fever $\left(\geq 38^{\circ} \mathrm{C}\right)$ & 29 (87.9) & $18(94.7)$ & $47(90.4)$ & $0.641^{c}$ \\
\hline Convulsion & $1(3.0)$ & $0(0.0)$ & $1(1.9)$ & $1.000^{c}$ \\
\hline Shiver & $9(27.3)$ & $2(10.5)$ & $11(21.2)$ & $0.284^{b}$ \\
\hline Cough & $33(100.0)$ & $18(94.7)$ & $51(98.1)$ & $0.365^{c}$ \\
\hline Nasal obstruction & $7(21.2)$ & $3(15.8)$ & $10(19.2)$ & $0.910^{b}$ \\
\hline Rhinorrhoea & $14(42.4)$ & $10(52.6)$ & $24(46.2)$ & $0.477^{\mathrm{a}}$ \\
\hline Sneeze & $8(24.2)$ & $6(31.6)$ & 14 (26.9) & $0.566^{\mathrm{a}}$ \\
\hline Vomit & $7(21.2)$ & $1(5.3)$ & $8(15.4)$ & $0.256^{b}$ \\
\hline Diarrhea & $1(3.0)$ & $1(5.3)$ & $2(3.9)$ & $1.000^{c}$ \\
\hline
\end{tabular}

be different in across regions and years. Therefore, it is necessary to establish continuous epidemiological surveillance in a wider area. The detection rates of HMPV infection between male and female patients in our study were not significantly different $(p=0.251)$, but there was a significance difference in the detection rates among age groups, with patients aged $\leq 4$ years $(4.8 \%)$ having a higher rate of detection compared with the patients aged $5-14$ years $(1.7 \%)(p=0.001)$. Notably, $90.4 \%$ of HMPV infections detected in this study occurred in patients aged $\leq 4$ years, which is consistent with findings from prior studies $[4,15]$. The peak age range for HMPV infections was $1-2$ years $(6.6 \%)$.

HMPV infections have a clear tendency toward seasonal distribution, supported by the result of the present study $(p=0.000)$, but they vary based on different climate and geography factors. Here, HMPV was detected most frequently in the winter and spring. The HMPV detection rate was highest in March 2018, which is similar to findings from studies in Lanzhou (China) and Korea $[18,19]$.

Co-infection with respiratory viruses and bacteria is commonly seen in cases of ARTIs. Coinfections of HMPV with other respiratory viruses have been reported many times, and patients with such co-infections are more likely to have a fever, lead to severe pneumonia, and cause higher hospitalization rates $[4,18,20]$. The proportion of co-infection in this study was $36.5 \%$. IFV and RSV were the most frequently co-infected viruses, which may be related to the overlap between the epidemic season of HMPV with those of IFV and RSV [21]. There was no significance difference observed between the co-infection group and mono-infection group in any of the assessed clinical manifestations, diagnoses, or hospital stay length. Peng et al. indicated that a high HMPV copy number is correlated with disease severity and hospital stay duration [22]; however, we did not find any relationship between the HMPV viral load and clinical features. There are also studies reporting that the viral load of asymptomatic children infected with HMPV is significantly lower than that of symptomatic children [23], which needs to be verified in future studies.

HMPV infection can cause both URTI and LRTI [3]. The risk factors associated with severe HMPV infection include preterm birth, early age, low immune function, nosocomial infection, and chronic pulmonary, cardiopathy, or neurological disease [24]. In the present study, all HMPV-infected patients had an URTI, 55.8\% had pneumonia, and $44.2 \%$ had bronchitis. Additionally, $94.2 \%$ of HMPV-positive children had an abnormal chest radiograph, and the main clinical characteristics of HMPV infection were cough, fever, and rhinorrhoea. No severe cases were found in our cohort, and $78.9 \%$ of our patients were discharged within 7 days.

HMPV can be divided into genotypes A and B. Vicente et al. reported that type A HMPV is more virulent than type B, whereas Papenburg et al. concluded that type B HMPV was associated with severe infection $[25,26]$, and some studies found no evidence for differential severity among different HMPV genotypes [18]. In the present study, we found patients with HMPV genotype A infection had a higher viral load compared to genotype B patients $(p=0.029)$, which is consistent with Oong's 


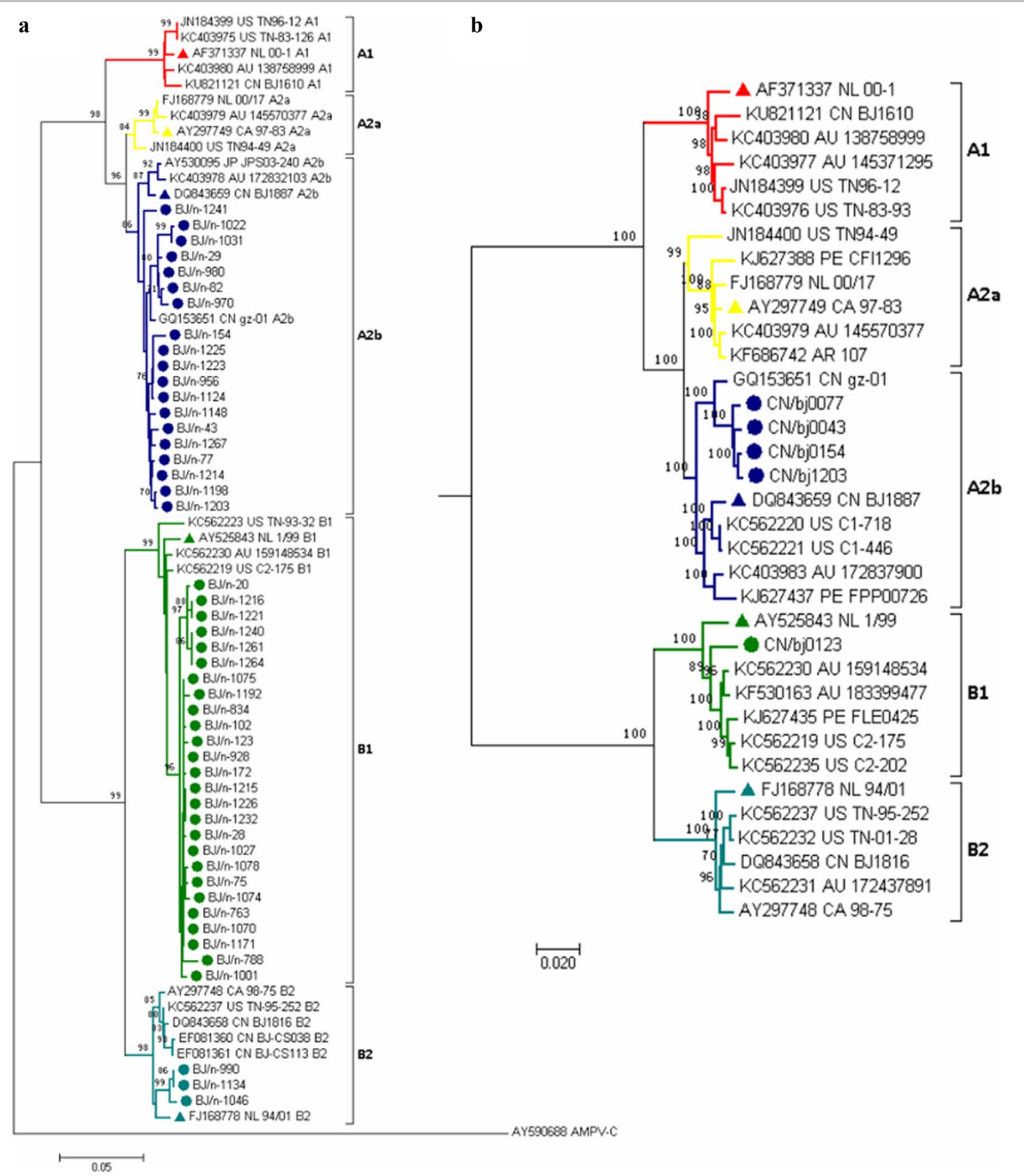

Fig. 3 Phylogenetic relationships of the strains detected in HMPV-infected children. a NJ-tree constructed based on the partial $\mathrm{N}$ gene sequences (813 bp) of HMPV strains. b NJ-tree constructed based on the whole genome sequences of HMPV strains. The reference strain is marked with a $\mathbf{A}$, and the strains analysed in this study are marked with $\mathbf{0}$. The country of origin for each reference and sample sequence is indicated by the following country codes: AR, Argentina; AU, Australia; CA, Canada; CN, China; JP, Japan; NL, Netherlands; PE, Peru; and US, United States of America

report [27]. However, there was no significant difference between HMPV genotypes A and B in terms of their epidemiological characteristics, hospital stay, or viral loads. We analysed the distribution of HMPV subtypes in Beijing based on a partial sequence of the $\mathrm{N}$ gene. Subtypes
$\mathrm{A} 2 \mathrm{~b}, \mathrm{~B} 1$, and $\mathrm{B} 2$ were detected, but subtypes $\mathrm{A} 1$ and A2a were not found. The most prevalent subtype was B1 (54.5\%), followed by A2b (40.9\%), which is consistent with previous work conducted in Beijing, Changsha, Kuala Lumpur, and Jordanian [7, 14, 28, 29]. 
Finally, to study the genome variation of HMPV epidemic strains in Beijing, we obtained five complete HMPV genome sequences with $80.1-99.6 \%$ identity, and four of them have an identity of 99.1-99.6\%. Phylogenetic tree results show that four strains belong to sublineage $\mathrm{A} 2 \mathrm{~b}$ and have the closest genetic distance to the gz-01 (China) strain, one strain belongs to sublineage B1, which is the first report of whole genome sequence of HMPVB1 isolated in China. No recombination events or mutations in important function sites were found.

The study is limited by the lack of a control group without ARTIs and its short research duration. Followup studies with long-term continuous monitoring that include a control group are needed to analyse the clinical features more accurately.

\section{Conclusion}

HMPV is an important virus in paediatric patients. The findings provide characteristics about the epidemiological and genotypic diversity of HMPV infections in Beijing, which will help to provide a theoretical basis for the prevention and control of diseases and to enrich the HMPV genome database of China.

\section{Supplementary Information}

The online version contains supplementary material available at https://doi. org/10.1186/s12985-021-01508-0.

Additional file 1. The fasta data of the $48 \mathrm{~N}$ gene sequences.

\begin{abstract}
Abbreviations
ADV: Adenovirus; AMPV: Avian metapneumovirus; ARTIs: Acute respiratory tract infections; $\mathrm{HBoV}$ : Human bocavirus; $\mathrm{HCoV}$ : Human coronavirus; HMPV: Human metapneumovirus; HPIVs: Human parainfluenza viruses; HRV: Human rhinovirus; IFV-A: Influenza A; LRTI: Lower respiratory tract infection; MEGA: Molecular evolutionary genetics analysis; NJ: Neighbour-joining method; NPAs: Nasopharyngeal aspirates; qRT-PCR: Real-time reverse transcription PCR; RNA: Ribonucleic acid; RSV: Respiratory syncytial virus; RT-PCR: Reverse transcription polymerase chain reaction; SPSS: Statistical product and service solutions; URTI: Upper respiratory tract infection; WUPyV: WU polyomavirus.
\end{abstract}

\section{Acknowledgements}

We thank the Department of Pediatrics, Beijing Friendship Hospital (Capital Medical University) for providing the NPA specimens. We also thank Katie Oakley, Ph.D., from Liwen Bianji, Edanz Editing China (www.liwenbianji.cn/ac), for editing the English text of a draft of this manuscript.

\section{Authors' contributions}

CW, TLW and LSZ conceived and designed the experiments. CW, FLM, HW JQG and AJC performed the experiments. CW, YMH and ZPX analyzed the data; CW, TLW and ZPX contributed reagents/materials/analysis tools; CW and LSZ wrote the manuscript. All authors read and approved the final manuscript.

\section{Funding}

This work was supported by the Key Technologies R\&D Program of the National Ministry of Science, China (2018ZX10305410-003-002, 2017ZX10104001, 2018ZX10713002). The funding body played no role in the design of the study and collection, analysis, and interpretation of data and in writing the manuscript.

\section{Availability of data and materials}

Condensed anonymized data are available from the corresponding author on reasonable request.

\section{Ethics approval and consent to participate}

The project was approved by the Ethical Committee of National Institute for Viral Disease Control and Prevention, China CDC, and the committee's reference number is IVDC2018-012

\section{Consent for publication}

Written informed consent for specimen collection, testing and publication was obtained from all individuals (or their parents) in the study population.

\section{Competing interests}

The authors declare that they have no competing interests.

\section{Author details}

NHC Key Laboratory of Medical Virology and Viral Diseases, National Institute for Viral Disease Control and Prevention, China CDC, Beijing, China. ${ }^{2}$ Department of Pediatrics, Beijing Friendship Hospital, Capital Medical University, Beijing, China. ${ }^{3}$ Center for Biosafety Mega-Science, Chinese Academy of Sciences, Beijing, China.

Received: 14 October 2020 Accepted: 8 February 2021

Published online: 18 February 2021

\section{References}

1. van den Hoogen BG, de Jong JC, Groen J, Kuiken T, de Groot R, Fouchier $R A$, et al. A newly discovered human pneumovirus isolated from young children with respiratory tract disease. Nat Med. 2001;7(6):719-24.

2. Hamelin ME, Abed Y, Boivin G. Human metapneumovirus: a new player among respiratory viruses. Clin Infect Dis. 2004;38(7):983-90.

3. Shafagati N, Williams J. Human metapneumovirus - what we know now. F1000Res. 2018;7:135.

4. Zhang L, Liu W, Liu D, Chen D, Tan W, Qiu S, et al. Epidemiological and clinical features of human metapneumovirus in hospitalised paediatric patients with acute respiratory illness: a cross-sectional study in Southern China, from 2013 to 2016. BMJ Open. 2018;8(2):e019308.

5. van den Hoogen BG, Herfst S, Sprong L, Cane PA, Forleo-Neto E, de Swart $\mathrm{RL}$, et al. Antigenic and genetic variability of human metapneumoviruses. Emerg Infect Dis. 2004;10(4):658-66.

6. Huck B, Scharf G, Neumann-Haefelin D, Puppe W, Weigl J, Falcone V. Novel human metapneumovirus sublineage. Emerg Infect Dis. 2006:12(1):147-50.

7. Chow WZ, Chan YF, Oong XY, Ng LJ, Nor ES, Ng KT, et al. Genetic diversity, seasonality and transmission network of human metapneumovirus: identification of a unique sub-lineage of the fusion and attachment genes. Sci Rep. 2016;6:27730.

8. Jagušić M, Slović A, Ljubin-Sternak S, Mlinarić-Galinović G, Forčić D. Genetic diversity of human metapneumovirus in hospitalized children with acute respiratory infections in Croatia. J Med Virol. 2017;89(11):1885-93.

9. Divarathna MVM, Rafeek RAM, Noordeen F. A review on epidemiology and impact of human metapneumovirus infections in children using TIAB search strategy on PubMed and PubMed Central articles. Rev Med Virol. 2020;30(1):e2090.

10. Maertzdorf J, Wang CK, Brown JB, Quinto JD, Chu M, de Graaf M, et al. Real-time reverse transcriptase PCR assay for detection of human metapneumoviruses from all known genetic lineages. J Clin Microbiol. 2004;42(3):981-6.

11. Xue P, Zheng $W$, Zhang M, Zheng L. Development of real-time RT-PCR for human metapneumovirus. Acta Virol. 2011;55(3):285-6.

12. Schickli JH, Kaur J, Ulbrandt N, Spaete RR, Tang RS. An S101P substitution in the putative cleavage motif of the human metapneumovirus fusion protein is a major determinant for trypsin-independent growth in vero cells and does not alter tissue tropism in hamsters. J Virol. 2005;79(16):10678-89. 
13. Cseke G, Maginnis MS, Cox RG, Tollefson SJ, Podsiad AB, Wright DW, et al. Integrin alphavbeta1 promotes infection by human metapneumovirus. Proc Natl Acad Sci USA. 2009;106(5):1566-71.

14. Zhou JY, Peng Y, Peng XY, Gao HC, Sun YP, Xie LY, et al. Human bocavirus and human metapneumovirus in hospitalized children with lower respiratory tract illness in Changsha, China. Influenza Other Respir Viruses. 2018;12(2):279-86.

15. Jain S, Williams DJ, Arnold SR, Ampofo K, Bramley AM, Reed C, et al. Community-acquired pneumonia requiring hospitalization among U.S. children. N Engl J Med. 2015;372(9):835-45.

16. Jroundi I, Mahraoui C, Benmessaoud R, Moraleda C, Tligui H, Seffar M, et al. A comparison of human metapneumovirus and respiratory syncytial virus WHO-defined severe pneumonia in Moroccan children. Epidemiol Infect. 2016;144(3):516-26.

17. Wang F, Zhu RN, Qian Y, Deng J, Zhao LQ, Sun Y, et al. Human metapneumoviruses were isolated from infants and children with acute respiratory infections in Beijing. Zhonghua Er Ke Za Zhi. 2010;48(11):820-3 (Article in Chinese).

18. Xiao NG, Xie ZP, Zhang B, Yuan XH, Song JR, Gao HC, et al. Prevalence and clinical and molecular characterization of human metapneumovirus in children with acute respiratory infection in China. Pediatr Infect Dis J. 2010;29(2):131-4.

19. Choi EH, Lee HJ, Kim SJ, Eun BW, Kim NH, Lee JA, et al. The association of newly identified respiratory viruses with lower respiratory tract infections in Korean children, 2000-2005. Clin Infect Dis. 2006:43(5):585-92.

20. Semple MG, Cowell A, Dove W, Greensill J, McNamara PS, Halfhide C, et al. Dual infection of infants by human metapneumovirus and human respiratory syncytial virus is strongly associated with severe bronchiolitis. J Infect Dis. 2005;191(3):382-6.

21. Neemuchwala A, Duvvuri VR, Marchand-Austin A, Li A, Gubbay JB. Human metapneumovirus prevalence and molecular epidemiology in respiratory outbreaks in Ontario, Canada. J Med Virol. 2015;87(2):269-74.
22. Peng D, Zhao X, Liu E, Huang Y, Yang X, Zhao Y, et al. Analysis of viral load in children infected with human metapneumovirus. Iran J Pediatr. 2010;20(4):393-400.

23. Bosis S, Esposito S, Osterhaus AD, Tremolati E, Begliatti E, Tagliabue C, et al. Association between high nasopharyngeal viral load and disease severity in children with human metapneumovirus infection. J Clin Virol. 2008;42(3):286-90.

24. Panda S, Mohakud NK, Pena L, Kumar S. Human metapneumovirus: review of an important respiratory pathogen. Int J Infect Dis. 2014:25:45-52

25. Papenburg J, Carbonneau J, Isabel S, Bergeron MG, Williams JV, De Serres $\mathrm{G}$, et al. Genetic diversity and molecular evolution of the major human metapneumovirus surface glycoproteins over a decade. J Clin Virol. 2013:58(3):541-7.

26. Vicente D, Montes M, Cilla G, Perez-Yarza EG, Perez-Trallero E. Differences in clinical severity between genotype A and genotype B human metapneumovirus infection in children. Clin Infect Dis. 2006;42(12):e111-3.

27. Oong XY, Chook JB, Ng KT, Chow WZ, Chan KG, Hanafi NS, et al. The role of human Metapneumovirus genetic diversity and nasopharyngeal viral load on symptom severity in adults. Virol J. 2018:15(1):91.

28. Lu G, Li J, Xie Z, Liu C, Guo L, Vernet G, et al. Human metapneumovirus associated with community-acquired pneumonia in children in Beijing, China. J Med Virol. 2013;85(1):138-43.

29. Schuster JE, Khuri-Bulos N, Faouri S, Shehabi A, Johnson M, Wang $\mathrm{L}$, et al. Human metapneumovirus infection in Jordanian children: epidemiology and risk factors for severe disease. Pediatr Infect Dis J. 2015:34(12):1335-41.

\section{Publisher's Note}

Springer Nature remains neutral with regard to jurisdictional claims in published maps and institutional affiliations.
Ready to submit your research? Choose BMC and benefit from:

- fast, convenient online submission

- thorough peer review by experienced researchers in your field

- rapid publication on acceptance

- support for research data, including large and complex data types

- gold Open Access which fosters wider collaboration and increased citations

- maximum visibility for your research: over $100 \mathrm{M}$ website views per year

At BMC, research is always in progress.

Learn more biomedcentral.com/submissions 